\title{
IDENTIFICAZIONE E QUANTIFICAZIONE \\ MOLECOLARE DI UREAPLASMA SPP. \\ SU SECREZIONI RESPIRATORIE DI NEONATI PREMATURI CON RDS. RISULTATI PRELIMINARI
}

Cultrera R.', Giuliodori M.', Granchi D. ${ }^{2}$, Seraceni S.',

Contini C.',

'Sezione di Malattie Infettive, Dipartimento di Medicina Clinica e Sperimentale, Università degli Studi di Ferrara,

Via Fossato di Mortara 23, 44100 Ferrara;

${ }^{2}$ Laboratorio Fisiopatologia Impianti Ortopedici,

Centro di Ricerca Codivilla Putti, Bologna

Il ruolo di Ureaplasma urealyticum nella sindrome respiratoria (RDS) di neonati prematuri non è del tutto chiarito nonostante il suo riscontro nelle secrezioni respiratorie di questi pazienti non sia infrequente. Le difficoltà di isolamento dei microrganismi con i comuni sistemi colturali sono scarsamente sensibili e non specifici, mentre la PCR consente l'identificazione della specie anche direttamente dai campioni biologici con elevata sensibilità. La determinazione della carica di $U$. urealyticum consentirebbe di meglio definire il rapporto esistente tra questi microrganismi e la RDS. Abbiamo, pertanto, sviluppato e valutato l'applicazione di una real time-PCR mediante Light-cycler (LC-PCR) con metodica SYBR Green I impegando primers Ureaplasmaspecifici rivolti verso il gene ureasi direttamente su aspirati endotracheali (TA), sangue e liquido cefalo rachidiano (LCR) di neonati prematuri con (gruppo1) o senza RDS (gruppo 2). I risultati sono stati confrontati con quelli ottenuti mediante PCR tradizionale. U. urealyticum/U. parvum è stato evidenziato in 15/24 TA di neonati del gruppo 1 ed in 9/31 TA di quelli del gruppo 2 con una prevalenza maggiore di $U$. parvum nel gruppo 1 , mentre $U$. urealyticum è stato identificato solo nel gruppo 2. La LC-PCR ha confermato i risultati ottenuti in PCR dimostrando una maggiore sensibilità $(\mathrm{p}<0,002)$ rispetto alla PCR. La carica di DNA di Ureaplasma spp. è risultata maggiore nei neonati con RDS ed insufficienza ventilatoria. Mediante LC-PCR è stata riscontrata la presenza di una bassissima carica di Ureaplasma (0.42 CFU Eq/ml) su LCR di un paziente con RDS complicata da emorragia intraventricolare e negatività alla PCR tradizionale. Riteniamo che la LC-PCR possa considerarsi utile nel quantificare la carica ureaplasmica e permettere di seguire l'andamento dell'infezione a seguito di trattamenti chemioantibiotici.

Ricerca svolta con contributi delle Fondazioni CARIFE e CARICE (2004-2005) e del MIUR. 